\title{
Enfermeiros entre os funcionários dos Hospitais da Universidade de Coimbra, 1779 a 1797: particularidades e implicaçóes
}

Nurses in the staff of the Coimbra University Hospitals, 1779-1797: particu-

larities and implications

Enfermeros entre el personal de los Hospitales de la Universidad de Coimbra, de 1779 a 1797: particularidades e implicaciones

Paulo Joaquim Pina Queirós ${ }^{1}$

(D) https://orcid.org/0000-0003-1817-612X

Patricia Domínguez-Isabel ${ }^{2}$

(iD) https://orcid.org/0000-0001-6894-2270

Blanca Espina-Jerez ${ }^{2}$

(D) https://orcid.org/0000-0001-9961-072X

Elisabete Pinheiro Alves Mendes Fonseca ${ }^{1}$

(D) https://orcid.org/0000-0002-2566-8301

Sagrário Gómez-Cantarino ${ }^{2}$

(iD https://orcid.org/0000-0002-9640-0409

${ }^{1}$ Unidade de Investigação em Ciências da Saúde: Enfermagem (UICISA: E), Escola Superior de Enfermagem de Coimbra (ESEnfC), Coimbra, Portugal

${ }^{2}$ Universidade de Castilla La Mancha, Faculdade de Enfermagem e Fisioterapia de Toledo, Espanha
Autor de correspondência:

Paulo Joaquim Pina Queirós

E-mail: pauloqueiros@esenfc.pt

\section{Resumo}

Contexto: Os Hospitais da Universidade de Coimbra resultam da concentração de pequenos hospitais e são, nesta época, uma instituição de dimensôes significativas. Nos finais do século XVIII, em pleno iluminismo, os hospitais vivenciaram um processo de transição para a modernidade.

Objetivos: Descrever os funcionários que existiam nos Hospitais da Universidade de Coimbra nos finais do século XVIII. Analisar a evolução dos ofícios em presença e os seus posicionamentos relativos, com o foco nos enfermeiros.

Metodologia: Análise histórica, partindo de fontes publicadas, considerando os contextos e as linhas evolutivas de longa duração, construindo uma síntese interpretativa.

Resultados: Estamos em presença de quatro agrupamentos profissionais - cuidadores do corpo (enfermeiros, médicos e cirurgióes), cuidadores da alma (capelóes e sacristáos), serviços de apoio (ajudantes, serventes, cozinheiros, roupeira, lavadeira, despenseiro), e Serviços de segurança (porteiros, guardas e tronqueiro).

Conclusão: Verificou-se a presença de enfermeiros num processo de transição entre linhas de continuidade medieval, com enfermeiros-sangradores e enfermeiros-cozinheiros, e a diferenciaçáo ascendente com enfermeira dos partos e descendente com ajudantes das enfermarias.

Palavras-chave: história da enfermagem; hospitais; assistência pública

\section{Abstract}

Context: Resulting from the integration of small hospitals, the Coimbra University Hospitals were, at this time, an institution of significant size. At the end of the $18^{\text {th }}$ century, during the Age of Enlightenment, hospitals were undergoing a process of transition to modernity.

Objectives: To describe the staff of the Coimbra University Hospitals in the last decades of the $18^{\text {th }}$ century and analyze the evolution of the existing professions and compare their salaries and positions, while focusing on nurses.

Methodology: A historical analysis based on published sources, considering the contexts and long-lasting evolutionary lines while building an interpretative summary.

Results: Four professional groups were found and divided into treatment of the body - nurses, physicians, and surgeons; treatment of the soul - chaplains and sexton; support services - assistants, helpers, cooks, laundry maid, washerwoman, despenseiro; and security services - doorkeepers, guards, and tronqueiro.

Conclusion: It was possible to observe the presence of nurses during the transition between medieval continuity, with the continuance of bloodletting nurses and cook nurses, and the ascending differentiation of the delivery nurse and the descending differentiation of ward assistants.

Keywords: nursing history; hospitals; public assistance

Resumen

Marco contextual: Los Hospitales de la Universidad de Coímbra son el resultado de la concentración de pequeńos hospitales y son, en este momento, una institución de dimensiones significativas. A finales del siglo XVIII, en plena Ilustración, los hospitales experimentaron un proceso de transición a la modernidad. Objetivos: Describir al personal que existía en los Hospitales de la Universidad de Coímbra a finales del siglo XVIII. Analizar la evolución de los oficios en presencia y sus posicionamientos relativos, centrándose en los enfermeros.

Metodología: Análisis histórico, a partir de fuentes publicadas, se consideraron los contextos y las líneas evolutivas de larga duración, y se construyó una síntesis interpretativa.

Resultados: Se encontraron cuatro grupos profesionales, cuidadores del cuerpo (enfermeros, médicos y cirujanos), cuidadores del alma (capellanes y sacristanes), servicios de apoyo (ayudantes, sirvientes, cocineros, guardarropa, lavandera, mayordomo) y servicios de seguridad (porteros, guardias y tronqueiro - guardia del albergue).

Conclusión: Se verificó la presencia de enfermeros en un proceso de transición entre líneas de continuidad medieval, con enfermeros-sangradores y enfermeros-cocineros, y la diferenciación ascendente con el enfermero de partos y descendiente con los ayudantes de enfermería.
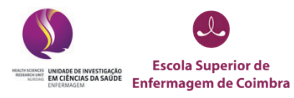

Como citar este artigo: Queirós, P. J., Domínguez-Isabel, P., Espina-Jerez, B., Fonseca, E. P. A. M, \& Gómez-Cantarino, S. (2020). Enfermeiros entre os funcionários dos Hospitais da Universidade de Coimbra, 1779 a 1797: particularidades e implicaçōes. Revista de Enfermagem Referência, 5(3), e20027. doi:10.12707/RV20027 


\section{Introduçáo}

O século XVIII português caracteriza-se por diversas linhas evolutivas de uma situação complexa em que se mistura as influências provenientes de outras naçôes europeias, por exemplo a Revolução Francesa de 1789-99, com acontecimentos relevantes no espaço ultramarino, como seja o florescimento do Brasil. Em Portugal aumenta a população, faz-se sentir a descoberta do ouro do Brasil, cresce o comércio e desenvolve-se o fomento agrícola, implementam-se industrias, desponta o movimento das luzes com efeitos concretos na segunda metade do século. Nestas circunstâncias, o país, oscila do absolutismo para o despotismo esclarecido. Transforma-se a sociedade em detrimento dos privilegiados a favor da burguesia. Um século marcado pela desuniáo, pela diversidade e por fortes mudanças socioeconómicas e culturais (Ramos, 2001). O século XVIII, entra na segunda metade, com a tragédia do terramoto de Lisboa em 1755, com repercussões em toda a nação, abrindo espaço à forte influência do Marquês de Pombal, verificando-se mudanças no ensino, reforma da Universidade de Coimbra, controlo da igreja pela realeza, perda de regalias e proventos eclesiásticos. $\mathrm{O}$ século XVIII, em Portugal, carateriza-se pela existência de "uma monarquia ora moderadamente despótica, ora ilustrada, ora híbrida (ou medianamente reformista), que teme e sente as primeiras ressonâncias ideológicas e militares da revolução gaulesa" (Ramos, 2001, p. 377). Na segunda metade do século XVIII, durante o reinado de D. José (1750-1777), com o Marquês de Pombal em primeiro-ministro, inaugura-se em Portugal a "intervenção reformadora e autoritária do Estado e do Governo em múltiplos domínios da sociedade" (Ramos, 2010, p. 377). Neste enquadramento, nas últimas décadas de oitocentos, encontramos os Hospitais da Universidade de Coimbra em funcionamento como hospital escolar, dependente da Universidade. Em 1772, com a reforma pombalina da Universidade de Coimbra "ao sistema de faculdades é agregado o conjunto de estabelecimento científicos, peça essencial da mudança. Manda-se criar o Hospital Escolar, o Teatro Anatómico, o Dispensário Farmacêutico..." (Gouveia, 1993, p. 439).

Em Coimbra existiam, pelo menos desde a baixa idade média, vários hospitais, alguns ainda antes da nacionalidade, como é o caso do Hospital de Milreu. Este, teve origem pelos anos 1064/1093, e funcionou autonomamente até 1526. Outros, surgiram logo nas origens de Portugal, como sejam, a título de exemplo, o Hospital de $S$. Nicolau (1144/1150 - 1504/1537), o Hospital S. Lázaro (1209/1210 - 1836), o Hospital Santa Elisabete da Hungria (1328/1333/1336 - 1559, data em que ruíram as instalaçóes), ou ainda Hospital de Nossa Senhora da Vitória em 1367.

Remonta a D. Manuel I, 1504, a iniciativa de concentração numa só instituição, de pequenos hospitais e albergarias existentes em Coimbra. Dessa iniciativa chega-nos um primeiro regimento do entâo designado Hospital Real, de 22 de outubro de 1508, posteriormente ampliado em 1510. D. Manuel "imprimiu uma nova fisionomia urbana a Coimbra, ao fundar o Hospital Real...” (Coelho, 1996, p. 225). Segundo Coelho, "Coimbra teria conhecido ao longo da Idade Média umas vinte e sete confrarias urbanas, treze albergarias, catorze hospitais e um gafaria de iniciativa real." (Coelho, 1996, p. 227).

Da nacionalidade até aos finais do século XV, a assistência pública fazia-se em albergarias, destinadas a peregrinos e a fazer muitas vezes funçóes de abrigo e hospital, em hospitais, desde cedo ao lado ou náo de albergarias, em gafarias, muito numerosas até ao século XIV, e em mercearias, destinadas à proteção de pessoas honradas, mas empobrecidas (Neto, 1989).

Sobre o enquadramento dos hospitais medievais sabemos que "era em casa que as pessoas se tratavam, não existindo hospitais tal como hoje se entende" (Oliveira, 2015, p. 181). Como refere Foucault "o personagem ideal do hospital, até o século XVIII, não é o doente que é preciso curar, mas o pobre que está morrendo. É alguém a que se deve assistir material e espiritualmente" (Foucault, 1984, p. 100).

Chegamos a meados do século XVIII, na cidade de Coimbra, com três instituiçóes hospitalares: o Hospital Real, o Hospital de S. Lázaro e o Hospital da Convalescença. Segundo Lopes (2000) o Hospital Real e o Hospital da Convalescença funcionavam no mesmo espaço, na Praça de S. Bartolomeu, e fora de portas o Hospital de S. Lázaro, na periferia urbana. O Hospital Real também é conhecido por Hospital Novo, Hospital de D. Manuel, Hospital da Cidade, Hospital da Praça, Hospital de S. Bartolomeu, Hospital de Nossa Senhora da Conceição, Hospital da Conceição.

Em 1512 o rei D. Manuel encarrega à Misericórdia de Coimbra a administração do Hospital Real. O que é certo, é que a Misericórdia nunca chegou a tomar posse do hospital, sendo que D. João III, em 1530, entregou o Hospital aos cónegos seculares de S. João Evangelista, conhecidos por Loios. Estes estiveram à frente do hospital até 1772 , com um curto interregno de 1741 a 1743 . A partir de 1769 , a procuradoria do hospital, deixa de pertencer à congregação dos Loios e, em 1772, o Marquês de Pombal ordena o sequestro de todos os seus bens e rendas, e a sua entrega à junta da fazenda da Universidade. Atente-se à política do Marquês de Pombal sobre a saúde pública, o seu provedor-mor da saúde, em Ordem Régia, de 12 de dezembro de 1776, escreve:

A saúde pública foi sempre um dos primeiros e mais importantes objetos da consideração em todas as naçôes mais iluminadas do mundo político, para estabelecerem, como têm estabelecido, as mais prontas e mais eficazes providencias, com que se conservassem os povos respetivos na maior felicidade que toda é dependente da mesma saúde pública. (Ordem Régia, 1776, p. 558)

Em 15 de abril de 1774 o Hospital Real é definitivamente entregue à Universidade de Coimbra. Em 1779, as instalaçôes do Hospital Real foram transferidas para o Colégio de Jesus, na Alta de Coimbra (Lopes, 2000). Em relação ao Hospital da Convalescença, embora existissem anteriores intençóes de criar um hospital para convalescentes, e de doaçóes testamentárias nesse sentido, só em 1764, este hospital, se estabelece totalmente à parte do Hospital Real. 
O Hospital de S. Lázaro, como já referido é uma instituição antiga, permanece na mesma zona, fora de portas, até 1836 , mas em 1774, em provisão de 15 de abril, é integrado nos Hospitais da Universidade de Coimbra (HUC). Refira-se, ainda a existência no espaço urbano de Coimbra, de uma albergaria para pedintes, instalada no piso baixo do Hospital Real, designado por Tronco e conhecida também por Hospital de Baixo para depois da segunda metade do século XVIII ser designada por Hospital Velho (Lopes, 2000).

Foucault considera que os hospitais medievais seriam "uma espécie de instrumento misto de exclusão, assistência e transformação espiritual” (Foucault, 1984, p. 100). Partindo desta apreciação, sobre a evolução dos hospitais até ao século XIX, Ferraz afirma que "estas características mantiveram-se até ao início do século XVIII, quando surgiu um novo conceito de hospital - o Hospital terapêutico - graças ao avanço da medicina, embora só no século XIX se conseguisse o objetivo terapêutico." (Ferraz, 2019, p. 159). Segundo Foucault "a consciência que o hospital pode e deve ser um instrumento destinado a curar aparece claramente em torno de 1780" (Foucault, 1984, p. 99). Para considerar que "antes do século XVIII, o hospital era essencialmente uma instituição de assistência aos pobres" (Foucault, 1984, p. 100).

O século XVIII fica também marcado no âmbito da história da enfermagem em Portugal pelo surgir, em 1741, do livro "Postilla Religiosa e Arte de Enfermeiros", um manual para enfermeiros da autoria de um enfermeiro, Frei Santiago. A sua relevância encontra-se também no facto da sua escrita transmitir uma perspetiva da enfermagem no final da primeira metade do século XVIII em Portugal (Santos, 2012). Afirma Santos que "continuamos com atividades onde a dependência de outros profissionais era elevada, surgindo alguns aspetos com alguma autonomia na sua execução" (Santos, 2012, p. 276-7).

Do regulamento do Hospital Real da Universidade de Coimbra de 1779, realça Santos (2012) que: "aos enfermeiros era dedicada uma parte específica, ao contrário do anterior, o que nos leva refletir uma vez mais sobre a dinâmica hospitalar, a valorização dos enfermeiros nas instituiçôes, ou do seu papel em termos organizacionais" (Santos, 2012, p. 280).

Estabelecemos como objetivos deste estudo, descrever os funcionários que existem nos HUC no último quartel do século XVIII, em particular, durante o período de 1779-1797. Analisar a evolução dos ofícios em presença e os seus posicionamentos relativos, com enfoque nos enfermeiros.

\section{Metodologia}

Estudo histórico descritivo com origem na análise e interpretação de fontes publicadas em quadros resumos dos funcionários dos HUC (Hospital da Conceição / Hospital Real e Hospital S. Lázaro), para os anos 1779, 1786 e 1790/1797. Enquadramento da análise produzida no lento surgimento e transformação do ofício de enfermeiro em profissão, numa visão estrutural. Com a necessária análise contextual dos ofícios e profissóes de saúde, com especial atenção aos enfermeiros e enfermeiras, assim como à evolução das instituiçóes de saúde nesse corte temporal e das políticas assistenciais à época.

As fontes utilizadas encontram-se publicadas por Lopes (2000) e referem-se aos funcionários dos HUC, em três séries: Hospital da Conceição e Hospital S. Lázaro, em 1779; funcionários dos HUC em (Hospital Real e S. Lázaro), em 1786; e Hospital Real e S. Lázaro de 1790 a 1797.

Reconfiguraram-se os quadros disponibilizados nestas fontes, de forma a facilitar a aferição dos funcionários em presença, dos vencimentos e sua evolução, das comparaçôes relativas dos vencimentos e funçôes, procurando posicionamentos hierárquicos, verificando elementos de continuidade do passado medieval, e sinais de modernidade. Construiu-se um texto interpretativo com as necessárias conclusôes.

\section{Resultados e Discussão}

O material empírico, as fontes, permitem desde logo, num primeiro apontamento considerar, que para a época, os HUC são uma grande instituição. Pela análise da tipologia dos funcionários perceciona-se um nível de organização estruturado, diferenciado nos supostos papéis desenvolvidos pelos agentes em presença.

Não por acaso, os dados deste hospital são fruto de uma política anterior de centralização hospitalar, com mais de dois séculos e meio de vivência. Em 1508, D. Manuel I, em Coimbra, leva a cabo a centralização hospitalar com a abertura do Hospital Real reunindo vários pequenos hospitais. Este movimento centralizador foi iniciado por D. João II após a receção da bula papal Injunctum nobis em 1486. Essa bula autorizava-o a padronizar e concentrar os hospitais em todo o país (Rossa, 2001).

Este movimento concretizou-se também em Lisboa, um pouco antes (1492-1504), com a reunião de pequenos hospitais no Hospital de Todos os Santos, "integrando a assistência numa nova dimensão, a do estado, com uma perspetiva que vai além da motivação religiosa” (Ferraz, 2019, p. 167). Notamos alguma distância aos hospitais modernos do século XIX em que, na sua estruturação, muito ficaram a dever às teorias higienistas, acompanhando-se de um nível de diferenciação das funçóes e dos seus funcionários, evoluindo posteriormente para uma hiperespecialização bem expressiva na atualidade.

A ilustrar esta afirmação verificamos alguma indiferenciação entre funçóes, nomeadamente de enfermeiro e de sangrador, também de enfermeiras a acumular com cozinheiras, no Hospital de S. Lázaro em 1779.

Por outro lado, o anúncio de alguma especializaçáo, com a significativa presença da enfermeira dos partos em 1791, no Hospital Real. Dado relevante, prelúdio de uma evolução profissionalizante, que sabemos ocorre, no caso especifico da enfermagem, num movimento lento, secular, e que no espaço português só pelos finais do século XX, se poderá considerar concluído em função da aprovação do regulamento do exercício da profissão de enfermagem, a criação do órgão regulador - Ordem dos Enfermeiros, e 
a formação de enfermeiros no ensino superior.

Nestes anos, de 1779 a 1797, encontramos enfermeiros, entre os funcionários em presença, profissionais, no sentido sociológico mais lato. O conceito de profissional de enfermagem em sentido restrito, ligado à noção de profissão de enfermagem é algo, que só em bom rigor, começa a ser referido nos textos e documentos mais perto da nossa época. Não que não existissem enfermeiros, mas o termo enfermagem, que designa o grupo, só ganha amplitude e começa a surgir, sem tibiezas, nos documentos nos finais de XIX e sobretudo inícios do século XX (Queirós, Almeida-Filho, Monteiro, Santos, \& Peres, 2017).

Existiam enfermeiros sem existir enfermagem enquanto coletivo profissional organizado como tal. Encontramos referência a enfermeiros, por exemplo, na enfermaria - domus infirmorum - do Mosteiro de Santa Cruz de Coimbra e no seu Hospital de São Nicolau, com o cargo de infirmarius. Aqui a enfermaria é da segunda metade do século XII, mas a referência explicita a infirmarius, por certo um pouco mais tardia (Silva, 2015).

A este propósito Carvalho afirma: "De qualquer modo podemos afirmar que a figura do infirmarius surgiu como ofício monástico, com as respetivas funçôes escritas, entre 1070 e 1080, no mosteiro de Cluny." (Carvalho, 2016, p. 71).

Encontramos a referência a enfermeiros, também, em documentos do século XIII, como por exemplo em 1257 "Plas G. ramiris infirmarios fratri rudericus" (Souto Cabo, 2003 , p. 80), ou em 1260 "Garsia. móógo enfermeyro" (Souto Cabo, 2003, p. 132), ou em "1268 "Johã perez enfermeiro" (Souto Cabo, 2003, p. 327), ou ainda 1269 "Maria. 'fonso enfermeyra." (Souto Cabo, 2003, p. 336). Analisando os funcionários nas três séries, nestas duas últimas décadas do século XVIII, verificamos a presença nos HUC de quatro agrupamentos de funcionários e uma singularidade.

Um primeiro agrupamento da esfera clínica, utilizando um termo atual, ou se quisermos de cuidadores do corpo, com médicos, cirurgióes, enfermeiros, enfermeiras, uma enfermeira dos partos e ajudantes de enfermaria de ambos os sexos. Um segundo agrupamento com os curadores da alma, onde incluiríamos capelóes e sacristãos. Um terceiro agrupamento compóe-se do conjunto de funcionários, cujo ofício se expressa em serviços de apoio, logística, ou seja, para garantir amenidades, referimo-nos a homens e mulheres serventes, despenseiro, por vezes a acumular com comprador e seu ajudante, homens e mulheres cozinheiras e seus ajudantes, roupeira e lavadeira. Num quarto agrupamento englobamos funçóes de segurança, logo identificamos e incluímos, guarda da porta e porteiros de ambos os sexos, e o tronqueiro da albergaria (conforme referido na introdução reporta-se ao chamado Hospital de Baixo).

A singularidade refere-se ao contínuo das aulas, pois trata-se de um hospital escolar. Em provisão de 21 de outubro de 1772, o Marquês de Pombal, ordena o sequestro de todos os bens e rendas do Hospital Real e a sua entrega à junta da fazenda da Universidade de Coimbra. Em abril de 1774 o Hospital real é definitivamente entregue à Universidade (Lopes, 2000). A função de ensino, em
1779, está bem presente com o contínuo das aulas, qual bedel da atualidade. Se seguirmos os critérios de Foucault (1984) caraterizadores do hospital moderno, como sejam, a deslocação do médico para o interior do hospital, e o ensino da medicina no hospital, constatamos que os HUC, nesta data, viviam uma transição, entre o hospital medieval e o hospital moderno, pois ainda não têm a internalização do médico, mas já fazem ensino médico no espaço assistencial.

Podemos constatar uma maior presença de funcionários no Hospital da Conceição e no Hospital Real, diríamos o núcleo central deste complexo hospitalar, do que no Hospital de S. Lázaro, estabelecimento diferenciado, no espaço e na função para tratamento e residência de pessoas com doença de Hansen. A dimensão é diferente, um central, outro periférico, o número de pessoa em cada função também, assim como o leque de ofícios.

Outro tópico de análise que devemos registar é a presença de ambos os sexos para algumas funçóes. No entanto, o mesmo não se verifica, e a expectativa já era essa, para profissões como médico, cirurgião, capelão, sacristão e despenseiro/comprador. Sabemos que o acesso às profissões médico/cirurgiāo para o sexo feminino é algo dos finais do século XIX. Como é o caso em Portugal de Elisa Augusta da Conceição Andrade, natural de Lisboa, que frequentou a Escola Politécnica de Lisboa, onde se matriculou em 1880, com 25 anos, e terá terminado o curso em 1889, sendo assim a primeira médica portuguesa (Cabral, 2016).

No mesmo espaço ibérico, no Andaluz, mas em ambiente cultural diferente, já não cristão, mas muçulmano, o acesso feminino à profissão médica é bem anterior ao corte temporal das duas últimas décadas do século XVIII. Durante os séculos X-XIV, houve diferentes formas de acesso à educação para a saúde. Especificamente, são conhecidos dois casos de mulheres médicas (árabe: tabiba) que se formaram pela via da linhagem (Espina-Jerez, Domínguez-Isabel, Gómez-Cantarino, Queirós, \& Bouzas-Mosquera, 2019). Umm cAmr bint Abī Marwān Ibn Zuhr (557 / 1162) filha do famoso Ibn Zuhr (Avenzoar) atendia a menores e mulheres da corte Almóada, embora também fosse consultada por questôes ginecológicas femininas. Dois séculos depois, há evidências de Umm al-Hasan al-Ṭanŷāilyya (séc. XIV), formada em medicina através de seu pai, e reconhecida pelo vizir e médico Ibn al-Jațīb (713-776 / 1313-1374; Olmo \& Vidal, 2012). Claro que a diferenciação sexual, para as funçôes espirituais, capelóes e sacristâos, não é expetável. Sendo ou não previsível, a função de despenseiro e por vezes comprador aparece também só no masculino. Neste aspeto, ligam-se estes três ofícios em algo comum, a diferenciação de status, hierarquicamente superior, e por isso naturalmente, para a época com expressão só no masculino.

Há ainda, a referir, a internalização da função religiosa, para o tratamento da alma, com capelães de sacristãos, e a internalização da função assistencial para o tratamento do corpo, assente na presença de enfermeiros, enfermeiras e ajudantes de enfermaria. Esta dualidade do tratamento corpo/alma persiste desde a idade média, sendo que bem se sabe que a internalização da função médica e 
do cirurgião, é de facto posterior, a este corte temporal. Cuidar do corpo e da alma desde a alta idade média, liga-se, entende-se e expressa-se nas presenças dentro das instituiçôes assistenciais. Sobre enfermeiros religiosos nos hospitais, como refere Lopes: "antes do século XIX não havia em Portugal enfermeiras hospitalares de ordens ou congregações religiosas, os frades enfermeiros em hospitais eram residuais" (Lopes, 2019, p. 155).

Os médicos e cirurgiōes estariam de chamada, vivendo perto, mas náo dentro, prestando serviço, mas não em exclusividade. Lembremo-nos que só no hospital moderno, finais de XVIII, início de XIX é que aparece "a personagem do médico de hospital que antes não havia" (Foucault,1984, p. 109). Numa visão atenta, o rol dos funcionários médicos do hospital do núcleo central (Conceição/Real) não regista unidades, precisamente, pelo que atrás foi referido. Não há médicos nos hospitais do núcleo central, Conceição e Real? Certo que há, mas em regime de não funcionários. Neste aspeto, mantém-se, ainda por essas datas uma tradição medieval "os hospitais e as enfermarias não eram locais de prática médica regular até ao final da Idade Média. Só muito raramente um clínico encontrar-se-ia num estabelecimento desta natureza" (Silva, 2015, p. 110).

Por outro lado, a função cirurgiáo tem presença no leque de funçóes (em 1779 e 1790/1797), mas seguindo a mesma linha de raciocínio, os cirurgiôes estaria em processo de diferenciação, num status inferior ao médico, por isso internalizado. Verifique-se a existência de enfermeiros e ajudantes de enfermaria a acumular com os estudos de cirurgia, ao mesmo tempo que enfermeiros ainda são também sangradores e acumulando no caso de $S$. Lázaro com as funçôes de cozinheira. Observa-se, mas não estranha, a presença forte no rol de funcionário, dos ofícios de serviços de apoio e segurança, facto que podemos considerar indiciador de modernidade, pela diversificação. Para o tratamento espiritual, da alma, temos dois capelóes e um sacristão com presença nas três datas em análise, mas apenas no Hospital da Conceição/Real. Em S. Lázaro não há registo para estas funçôes. Instituiçẫo de menor dimensão e mais perto de residencial - albergaria, do que de hospital, teria a satisfação da função espiritual com outros recursos.

Em relação aos enfermeiros e às enfermeiras aparecem com distinção de sexo e ao longo das três séries temporais, no Hospital da Conceição/Real, verificando-se, no entanto, em S. Lázaro omissão de enfermeira em 1786. No Hospital da Conceição/Real, os enfermeiros são em número de dois nas primeiras duas datas, aumentando para três na terceira, e as enfermeiras seguem com o número de duas nas três datas.

Esta presença de enfermeiros tem as seguintes particularidades: em 1779, no Hospital da Conceição os dois enfermeiros eram simultaneamente praticantes de cirurgia, nesta data e neste hospital, regista-se também um ajudante e uma ajudante das enfermarias que são também praticantes de cirurgia. Em 1786, o quadro de funcionário dos HUC regista um ajudante sem referir alocação a um sítio ou função mais discriminada. De forma curiosa, em S. Lázaro, 1779, o enfermeiro acumula com sangrador, é um enfermeiro-sangrador, e a enfermeira acumula com a função de cozinheira, função que repete em 1790/97. De forma significativa aparece em 1791 nos HUC um lugar para enfermeira dos partos.

Em relação a funçôes gerais, desde logo a referência a serventes com presença, nas três séries temporais, em número variável, mas com as seguintes particularidades: No Lazareto apenas há registo para serventes femininas, sendo que no Hospital da Conceição/Real estão mulheres e homens serventes, e também em número variável (Tabela 1).

Tabela 1

Funcionários dos HUC (Hospital da Conceição, Hospital Real e S.Lázaro)

\begin{tabular}{|c|c|c|c|c|c|c|}
\hline & \multicolumn{2}{|c|}{1779} & \multicolumn{2}{|c|}{1786} & \multicolumn{2}{|c|}{$1790-1797$} \\
\hline & Conceição & S. Lázaro & H. Real & S. Lázaro & H. Real & S. Lázaro \\
\hline Enfermeiros & $2(a)$ & $1(\mathrm{~b})$ & 2 & 1 & 3 & 1 \\
\hline Enfermeiras & 2 & $1(\mathrm{c})$ & 2 & & 2 & $1(\mathrm{c})$ \\
\hline Enfermeiras dos partos & & & & & $1(1791)$ & \\
\hline Ajud. de enfermaria $\widehat{\partial}(\mathrm{d})$ & 1 (a) & & (1) & & & \\
\hline Ajud. de enfermaria $q$ (d) & $1(\mathrm{a})$ & & & & & \\
\hline Servente homem & variável & & variável & & 3 & \\
\hline Servente mulher & variável & variável & 4 & variável & $2-3$ & 1 \\
\hline Cirurgião & 1 & & & & 1 & \\
\hline Médico & & & & 1 & & 1 \\
\hline Capelão & 2 & & 2 & & 2 & \\
\hline Sacristão & 1 & & 1 & & 1 & \\
\hline Porteiro & 2 & & & & & \\
\hline Porteira & 1 & & 1 & & 1 & \\
\hline Continuo das aulas & 1 & & 1 & & 1 & \\
\hline Guarda da porta & & & 1 & & 1 & \\
\hline
\end{tabular}




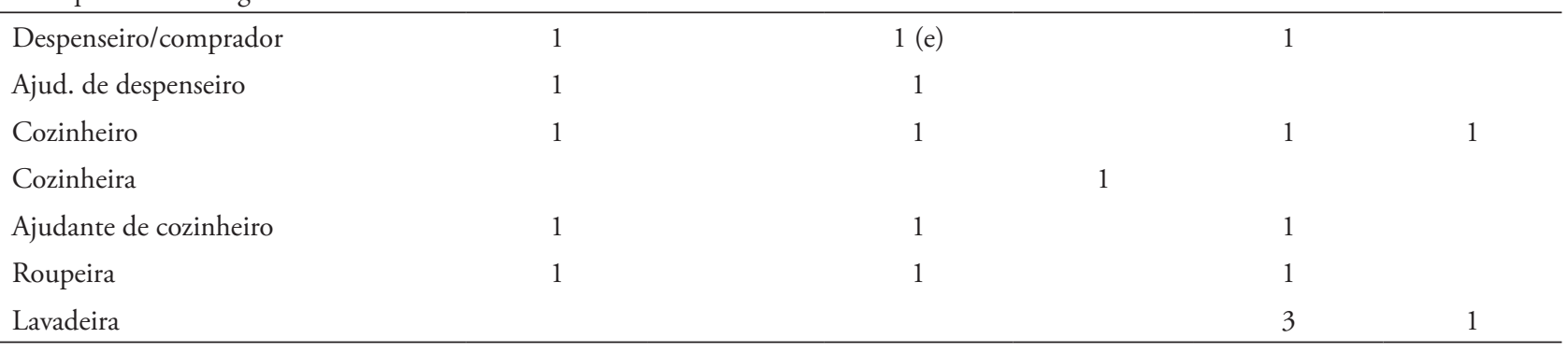

Nota. (a) = acumula com estudante de cirurgia; (b) = acumula com sangrador; (c) = acumula com cozinheira; (d) = pode fazer serviço de enfermeiro/a; (e) = despenseiro que acumula com comprador. Fonte: Reconfiguração, pelos autores, dos quadros publicados de "Pobreza, assistência e controlo social em Coimbra (1750-1850)", de Lopes, 2000. (2 vols.). Viseu, Portugal: Palimage (pp. 649, 650, 651).

Quando observamos o quadro com as remuneraçóes dos diversos ofícios importa perceber a hierarquia dos valores que por hipótese traduzem a importância social, e por outro lado, saber se houve alteração na hierarquia ao longo das três séries bem como progrediram os vencimentos ao longo dessas três datas.

Para a análise estaremos atentos aos vencimentos com o incluir das refeiçóes e os vencimentos a seco, ou seja, sem incluir a dieta.

Quanto à hierarquia, dos vencimentos mais elevados para os mais baixos, podemos registar que são os capelóes que tem os vencimentos mais elevados, seguidos dos cirurgiōes. A remuneração dos médicos, numa primeira análise é menor, mas atenda-se ao que já se referiu, no que diz respeito à sua não internalização e sua não exclusividade, estando previsivelmente em regime de chamada.

$\mathrm{O}$ despenseiro e o contínuo das aulas aparecem com remuneraçóes elevadas, o que corrobora o que afirmamos nos comentários anteriores, em relação, por um lado à posição na escala hierárquica do despenseiro e do seu ajudante. Verifique-se também o vencimento elevado deste comparando com outros ajudantes. Constatamos ainda que o lugar de continuo das aulas é um lugar por certo de prestígio, se assim não fosse, não teria vencimento também tão expressivo.

Tomando como referência as remuneraçóes dos enfermeiros, notamos que ofícios como porteiro, guarda da porta e cozinheiro auferem remuneração ligeiramente superior. Em relação aos vencimentos inferiores aos dos enfermeiros registamos os ajudantes de enfermarias, serventes e lavadeira. Numa análise horizontal verificamos que é nos venci- mentos de 1790 a 1797 , que se nota uma subida com significado em praticamente todos os ofícios quando comparado com as duas séries anteriores.

$\mathrm{Na}$ sequência destas três séries não nos parece haver alterações nos posicionamentos relativos de cada ofício, aferido pelos vencimentos auferidos, as posiçóes mantem-se indicado a não existência de mobilidade social, o que é natural num intervalo temporal de cerca de 20 anos.

Como regra geral, os vencimentos do Hospital de S. Lázaro são superiores ao do Hospital da Conceição/ Real, mas esta apreciação tem de contar que todos os remunerados em S. Lázaro o são sem alimentação, a seco. No Hospital da Conceição/ Real, sem alimentação incluída, por isso a seco, só o contínuo das aulas, em 1779 e os capelães em 1786 e 1790-1797. As posiçôes remuneratórias mais baixas eram ocupadas pelas serventes femininas, lavadeira e porteira do Hospital Real em 1790-1797. Serventes e ajudantes de enfermaria femininos ganham menos que os seus congéneres masculinos, já em relação às enfermeiras e cozinheira não é táo nítida a diferença em relação aos homens com a mesma função (Tabela 2).

Lopes, em publicação de 2019, analisando estes quadros de pessoal destaca:

no pequeno Hospital de S. Lázaro, tanto o enfermeiro como a enfermeira acumulavam a sua função com outra atividade; os enfermeiros do Hospital Real podiam conjugar o exercício da sua ocupação com a aprendizagem de cirurgia e esse benefício estendia-se às mulheres; por fim, estes enfermeiros recebiam menos do que os porteiros, o sacristão, o cozinheiro e o seu ajudante, a roupeira e até menos do que as enfermeiras. (Lopes, 2019, p. 163)

Tabela 2

Ordenados em réis, dos funcionários dos HUC (Hospital da Conceição, Hospital Real e S. Lázaro)

\begin{tabular}{|c|c|c|c|c|c|c|}
\hline & \multicolumn{2}{|c|}{1779} & \multicolumn{2}{|r|}{1786} & \multicolumn{2}{|c|}{$1790-1797$} \\
\hline & Conceição & S. Lázaro & H. Real & S. Lázaro & H. Real & S. Lázaro \\
\hline Enfermeiros & $60 / d(a)$ & $120 / \mathrm{d}(\mathrm{b})$ & $60 / d$ & $120 / \mathrm{d}$ & $80 / \mathrm{d}$ & 180-200/d \\
\hline Enfermeiras & $80 / d$ & $120 / \mathrm{d}(\mathrm{b})$ & $80 / \mathrm{d}$ & & $80 / \mathrm{d}$ & $140 / \mathrm{d}$ \\
\hline Enfermeiras dos partos & & & & & $80 / \mathrm{d}$ & \\
\hline Ajud. de enfermaria $\widehat{\sigma}$ & $80 / \mathrm{d}$ & & & & & \\
\hline Ajud. de enfermaria ${ }^{\circ}$ & $60 / \mathrm{d}$ & & & & & \\
\hline
\end{tabular}




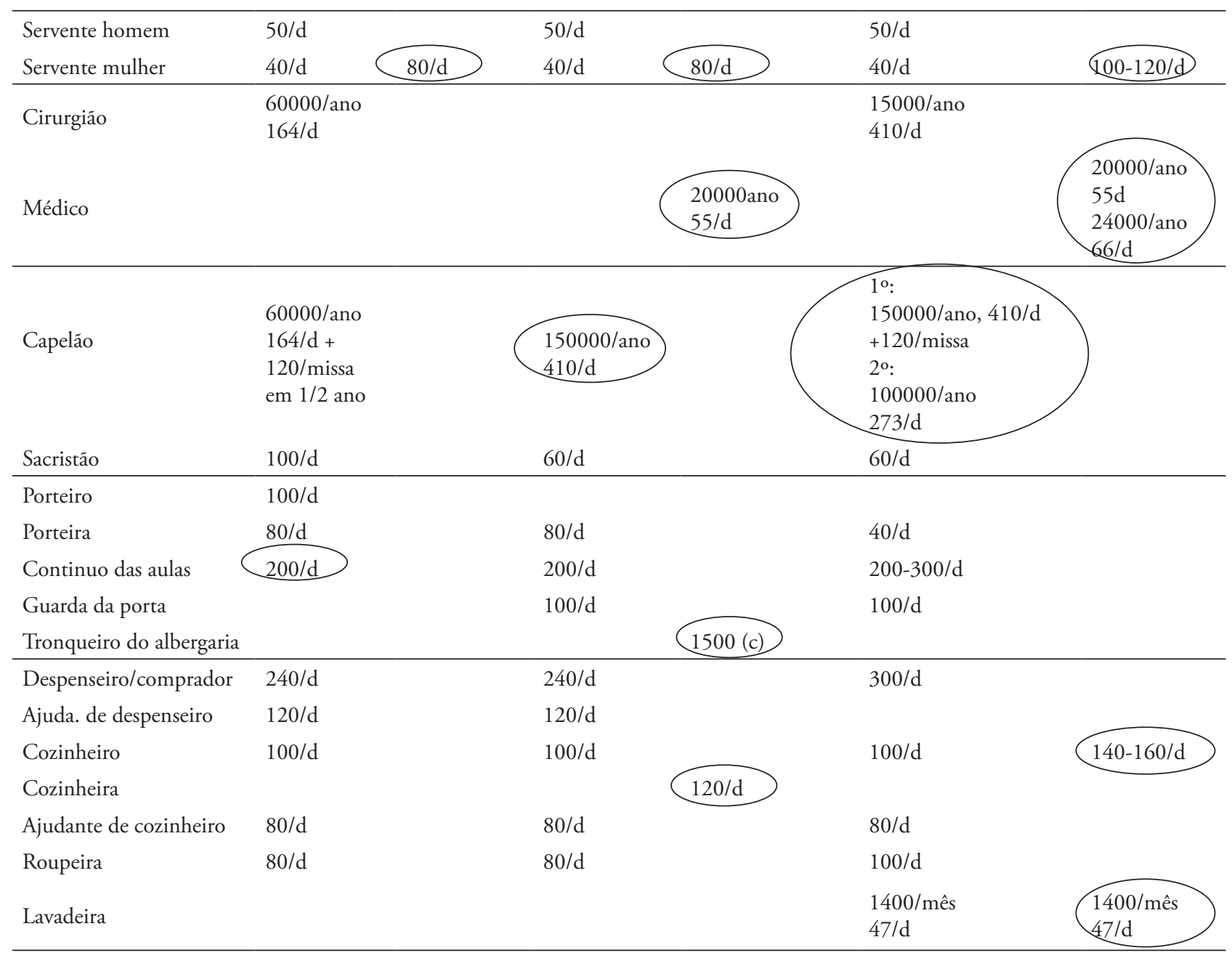

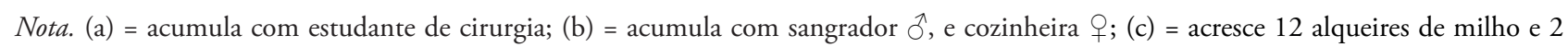
alqueires de azeite/ano.

$\bigcirc=a$ seco, sem dieta incluída. Fonte: Reconfiguração, pelos autores, dos quadros publicados de "Pobreza, assistência e controlo social em Coimbra (1750-1850)” ,de Lopes, 2000. (2 vols.). Viseu, Portugal: Palimage (pp. 649, 650, 651).

A análise das listas dos funcionários dos HUC (Hospital da Conceição, Hospital Real e S. Lázaro) e dos seus ordenados, permite comparaçóes intergrupais profissionais e a evoluçáo das diversas funções e profissóes em presença. Para além de um corte transversal informativo das duas décadas finais do século XVIII, para uma realidade geograficamente concentrada na cidade de Coimbra, numa instituição de assistência, de dimensão significativa e ligada à Universidade, quando considerado num friso longitudinal, dá contributos para a informação e esclarecimento do movimento secular de configuração de ofícios e profissôes assistências, bem como das modificaçóes das estruturas hospitalares. Da presença remota de enfermeiros chegamos à presença significativa nestas datas, com expressão em ambos os sexos, com níveis de estruturação interessantes, contando com diferenciação ascendente "enfermeira dos partos" e diferenciação descendente com ajudantes de enfermaria.

\section{Conclusão}

A análise das funçóes e dos vencimentos permite-nos estabelecer algumas sínteses.

Estamos perante uma organização hospitalar centralizada com a agregação de vários hospitais, existentes em espaços geográficos diferentes - urbanos e periféricos - que revelam um nível de estruturação visível pelo rol diversificado de profissóes e ofícios em presença. A lista de funcionários permite a sua caracterização em quatro agrupamentos: os clínicos para o tratamento do corpo; os curadores da alma; o dos serviços/ amenidades; o das funções de segurança. Pela particularidade identificámos uma função específica, a de contínuo das aulas.

Concluímos pela permanência de traços medievais e pelo alvor da modernidade. Por um lado, a expressar-se na presença de enfermeiros-sangradores e enfermeiras-cozinheiras, médicos externos à instituição, e por outro lado, a concretizar-se na diferenciação da enfermagem com o aparecimento da enfermeira dos partos e de ajudantes de enfermaria. Outro tópico a referir é a permanência 
de um programa assistencial com atenção ao corpo e à alma. A presença nas três séries para os dois hospitais de enfermeiros internalizados, com ajudantes e com uma diferenciação em enfermeira dos partos, denota estruturaçẫo das funçóes de enfermeiro.

\section{Contribuiçáo de autores}

Conceptualização: Queirós, P., Domínguez-Isabel, P. Tratamento de dados: Queirós, P., Domínguez-Isabel, P., Espina-Jerez, B., Fonseca, E.

Metodologia: Queirós, P., Domínguez-Isabel, P., Espina-Jerez, B.

Redação - preparação do rascunho original: Queirós, P., Domínguez-Isabel, P., Espina-Jerez, B.

Redação - revisão e edição: Queirós, P., Domínguez-Isabel, P., Espina-Jerez, B., Gómez-Cantarino, S.

\section{Referências Bibliográficas}

Cabral, J. M. (2016, Maio 9). A primeira médica portuguesa [Web log post]. Recuperado de https://portugaldeantigamente.blogs.sapo. pt/a-primeira-medica-portuguesa-32869:

Carvalho, A. (2016). O Infirmarius. Precursor medieval do enfermeiro. Pensar Enfermagem, 20(1), 63-78. Recuperado de http:// pensarenfermagem.esel.pt/files/Artigo5_63_78.pdf

Coelho, M. H. (1996). A assistência em Coimbra em tempos Manuelinos: O Hospital Novo. Biblos, 72, 223-258

Espina-Jerez, B., Domínguez-Isabel, P., Gómez-Cantarino, S., Queirós, P., \& Bouzas-Mosquera, C. (2019). Una excepción en la trayectoria formativa de las mujeres: Al-Ándalus en los siglos VIII-XII. Cultura de los Cuidados, 23(54), 194-205. doi:10.14198/cuid.2019.54.1 doi:10.14198/cuid.2019.54.17

Ferraz, I. (2019). Enfermidades, enfermos, enfermeiros. Dos primórdios ao século XIX. Lisboa, Portugal: Autor

Foucault, M. (1984). Microfisica do poder (4a ed.). Rio de Janeiro, Brasil: Edições Graal. Recuperado de http://www.cidadaniaereflexao. com.br/uems2018/Microfsica\%20do\%20Poder.pdf

Gouveia, A. C. (1993). Estratégias de interiorização da disciplina, pp. 415-440. In J. Mattoso (dir.), História de Portugal (vol. 4, pp. 415-440). Rio de Mouro, Portugal: Círculo de Leitores.

Lopes, M. A. (2019). Enfermeiros e enfermeiras nos hospitais portugueses dos séculos XVIII e XIX: Continuidades e ruturas. In A. Esteves (Coord.) Homens, Instituiçôes e Politicas (séculos XVI-XX). Braga, Portugal: Universidade do Minho.

Lopes, M. A. (2000). Pobreza, assistência e controlo social em Coimbra (1750-1850), (2 vols.). Viseu, Portugal: Palimage.

Neto, M. L. (1989). Assistência pública. In J. Serrão, Dicionário de História de Portugal (vol. I.). Porto, Portugal: Livraria Figueirinhas.

Oliveira, A. R. (2015). O dia-a-dia em Portugal na Idade Média. Lisboa, Portugal: A Esfera dos Livros.

Olmo, A. \& Vidal, F. (2012). Dos modelos de mujeres "sabias" andalusíes en la Loja nazarí. In IV Congreso Virtual sobre Historia de las Mujeres. Recuperado de https://dialnet.unirioja.es/servlet/ articulo? codigo $=4715145$

Ordem Régia (1776, 12 de dezembro). In Oliveira, E.F. (1911). Elementos para a História do Município de Lisboa (t. 17, p. 558). Lisboa, Portugal: Typographia Universal.

Queirós, P., Almeida-Filho, A., Monteiro, A. P., Santos, T., \& Peres, M. A. (2017). Debates parlamentares em Portugal de 1821 a 1910: Identificação de fontes para a história da enfermagem. Escola Anna Nery, 21(1), 1-6

Ramos, L. (2001). A Revolução das Luzes. In R. Carneiro, A. Matos (Coords.), Memória de Portugal. O Milénio Português (pp. 374423). Rio de Mouro, Portugal: Círculo de Leitores.

Ramos, R. (Coord.) (2010). História de Portugal (3a ed.). Lisboa, Portugal: A Esfera dos Livros.

Rossa, W. (2001). Divercidade - urbanografia do espaço de Coimbra até ao estabelecimento definitivo da Universidade (Tese de doutoramento). Universidade de Coimbra, Portugal.

Santos, L. F. (2012). Uma história de enfermagem em Portugal (11431973): A constância do essencial num mundo em evolução permanente (Tese de doutoramento). Universidade Católica Portuguesa, Portugal. Recuperado de https://repositorio.ucp.pt/ handle/10400.14/12265

Silva, A. (2015). Físicos e cirurgióes medievais portugueses. Contextos socioculturais, práticas e transmissão de conhecimentos (1192-1340) (Dissertaçáo de mestrado). Faculdade de Letras da Universidade do Porto, Portugal.

Souto Cabo, J. A. (2003). Documentos galego-portugueses dos séculos XII e XIII. Revista Galega de Filoloxia: Monografia 5. Recuperado de https://www.academia.edu/2627155/Documentos_galego-portugueses_dos_s\%C3\%A9culos_XII_e_XIII_1139-1270_ 